\title{
Plasma levels of matrix metalloproteinases 2 and 9 correlate with histological grade in breast cancer patients
}

\author{
FORTUNATA VASATURO ${ }^{1}$, FABIANA SOLAI ${ }^{2}$, CAROLINA MALACRINO $^{3}$, TIZIANA NARDO ${ }^{3}$, \\ BRUNO VINCENZI ${ }^{4}$, MAURO MODESTI ${ }^{2}$ and SUSANNA SCARPA ${ }^{3}$ \\ Departments of ${ }^{1}$ Emergency, ${ }^{2}$ Surgical Sciences and ${ }^{3}$ Experimental Medicine, University Sapienza; \\ ${ }^{4}$ Medical Oncology, University Campus Bio-Medico, Rome I-00161, Italy
}

Received May 2, 2012; Accepted July 30, 2012

DOI: $10.3892 / \mathrm{ol} .2012 .977$

\begin{abstract}
Matrix metalloproteinases (MMPs) are proteolytic enzymes involved in the process of tumor invasion and metastasis that are found throughout tissues and also in the plasma. The aim of this study was to investigate whether the evaluation of plasma concentrations of MMPs 2, 3 and 9 may have clinical significance in breast cancer. Therefore, sera obtained from 80 patients with breast neoplasia (50 carcinomas and 30 fibroadenomas) were collected before and $96 \mathrm{~h}$ after surgery and the concentrations of MMPs 2, 3 and 9 were quantified using an enzyme-linked immunosorbent assay (ELISA). The mean expression level of MMP 2 was significantly higher in carcinoma compared with that in fibroadenoma patients, while there was no significant difference for MMPs 3 and 9. In addition, the group of carcinoma patients was analyzed in order to compare the mean values for each MMP obtained before and after surgery. However, the differences between pre- and post-surgery values for all three MMPs were not statistically significant. Furthermore, the plasma levels of each MMP were correlated with certain clinicopathological parameters of the tumors and we observed a significant and direct correlation between the concentrations of MMPs 2 and 9 and tumor histological grade. These data suggest that the quantification of plasma MMP 2 and MMP 9 levels may provide additional clinical information of the tumor and it is, therefore, a possible prognostic index for breast cancer.
\end{abstract}

\section{Introduction}

The matrix metalloproteinases (MMPs) are a large family of highly homologous zinc-dependent endopeptidases, which play a fundamental role in extracellular matrix degradation and

Correspondence to: Professor Susanna Scarpa, Department of Experimental Medicine, University Sapienza, Viale Regina Elena 324, Rome I-00161, Italy

E-mail: susanna.scarpa@uniroma1.it

Key words: matrix metalloproteinase, breast cancer, plasma markers, tumor grade, histological grade remodeling (1). MMPs are ubiquitous in tissues and biological fluids and are produced by a wide variety of normal and tumoral cells. MMPs are synthesized as inactive proenzymes and require activation through a proteolytic mechanism; therefore, they are found within tissues and plasma as inactive precursors, active enzymes or inactive enzymes bound to specific inhibitors (2).

Extracellular matrix digestion and remodeling are required by tumor cells in order to migrate into the stroma and therefore these events are fundamental steps in tumor local invasion; furthermore, MMPs partially participate in tumor neoangiogenesis. Consequently, MMPs produced by either tumor cells or host peri-tumoral cells are directly involved in the stimulation of tumor invasion and metastasis $(3,4)$. MMPs are classified depending on the specificity of the degrading substrate, specifically MMPs 2 and 9 are named type IV collagenases, or alternatively gelatinase A and B, respectively. Their degrading substrates are gelatine, the denatured form of collagen, and type IV collagen, the main component of the basement membrane. MMP 3 is also known as stromelysin I and plays a key role in the tumor growth, as it degrades interstitial type I and III collagens. Many MMPs, in particular MMPs 2 and 9, are easily detected and quantified in body fluids. Several studies have been performed on the evaluation of plasma MMP concentrations in correlation with different diseases, including diabetes, atherosclerosis, inflammation and cancer. Of these studies, one was performed on breast cancer and revealed that the concentration of total MMP 2 and 9 was significantly higher in the plasma of patients with breast cancer compared with patients with benign breast diseases and the control groups (5). Another study performed on breast cancer demonstrated that the MMP 2 serum level was higher in patients positive for the estrogen receptor; furthermore, this study showed that a lower MMP 2 level was a predictor of disease-free and overall survival (6). Positive expression of MMPs 3, 2 and 9 has been reported to be correlated with the progression of breast cancer in a rat model and their levels were significantly higher in the metastatic brain tissue of rats with breast cancer compared with normal brain tissue (7). However, to date no study evaluating the concentration of MMP 3 in the plasma of tumor patients has been performed.

For this reason, we analyzed the plasma concentration of MMPs 2, 3 and 9, comparing patients with breast adenocar- 
cinomas with patients with breast fibroadenomas or normal controls. Plasma was collected $24 \mathrm{~h}$ before and $96 \mathrm{~h}$ after surgery and the concentration of each MMP was compared before and after surgery. Furthermore, the values of each MMP were correlated with biological and clinical parameters of the patients.

\section{Materials and methods}

Serum samples. Peripheral venous blood samples were collected from patients with breast neoplasia who underwent surgery at the Department of Surgical Sciences (University Sapienza, Rome, Italy). Informed consent was obtained from all patients. This study received the positive approval of the Ethic Committee of the Faculty of Medicine of the University Sapienza of Rome, Italy.

Blood sampling was performed $24 \mathrm{~h}$ before and $96 \mathrm{~h}$ after surgery. The venous blood was collected in tubes with EDTA-anticoagulants and were then centrifuged at 4,000 x g for $10 \mathrm{~min}$. The plasma was recovered, aliquoted and stored at $-80^{\circ} \mathrm{C}$ until analysis.

Enzyme-linked immunosorbent assay (ELISA). Plasma concentrations of MMPs were evaluated by the ELISA technique utilizing commercially available kits. For MMPs 2 and 9, the Quantikine ELISA kits (R\&D Systems, Minneapolis, MN, USA) were used and for MMP 3 the Human Biotrak Assay (Amersham Pharmacia Biotech, Amersham, UK) was used. All plasma samples and the negative controls and the samples for the standard curve were measured in duplicate and the mean was calculated. The ELISA method was performed according to the supplier's instructions and the sample concentrations were obtained from the standard curve. The absorbances were measured on a microplate reader at $450 \mathrm{~nm}$.

Statistical analysis. Data are expressed as mean \pm standard deviation (SD). The Mann-Whitney U test for unpaired samples, the Kruskal-Wallis test for multiple comparisons and the Spearman's rank correlation coefficent were used (SPSS 13.01 for Windows, SPSS Inc., Chicago, IL, USA; GraphPad Prism 4.0, GraphPad Software Inc., San Diego, CA, USA). $\mathrm{P}<0.05$ (two-sided) was considered to indicate a statistically significant result.

\section{Results}

A group of 80 patients with primary breast neoplasia, 50 with carcinoma and 30 with fibroadenoma, were selected for the present study. The clinical and biological data of all carcinoma patients were obtained and are listed in Table I; $\mathrm{T}$ and $\mathrm{N}$ factors, histological grade, Ki67 levels and status of estrogen and progesterone receptors and Her2/neu were considered.

Comparison of plasmatic MMPs 2, 3 and 9 between breast cancer and fibroadenoma. Plasma was collected from each patient $24 \mathrm{~h}$ before and $96 \mathrm{~h}$ after surgery and the concentrations of MMPs 2, 3 and 9 were quantified by ELISA. The mean values were then calculated for each group of patients, i.e., carcinomas and fibroadenomas. The mean concentrations
Table I. Patient characteristics.

\begin{tabular}{|c|c|c|}
\hline Characteristic & $\mathrm{n}$ & $\%$ \\
\hline Total & 80 & \\
\hline \multicolumn{3}{|l|}{ Diagnosis } \\
\hline Breast cancer & 50 & \\
\hline Breast fibroadenoma & 30 & \\
\hline \multicolumn{3}{|l|}{$\mathrm{T}$ factor } \\
\hline $\mathrm{T} 1$ & 28 & 56 \\
\hline $\mathrm{T} 2$ & 15 & 30 \\
\hline T3 & 6 & 12 \\
\hline $\mathrm{T} 4$ & 1 & 2 \\
\hline \multicolumn{3}{|l|}{$\mathrm{N}$ factor } \\
\hline N- & 34 & 68 \\
\hline $\mathrm{N}+$ & 16 & 32 \\
\hline \multicolumn{3}{|l|}{ Grading } \\
\hline G1 & 6 & 12 \\
\hline $\mathrm{G} 2$ & 17 & 34 \\
\hline G3 & 27 & 54 \\
\hline \multicolumn{3}{|l|}{ Ki67 (cut-off 10\%) } \\
\hline Negative & 18 & 36 \\
\hline Positive & 32 & 64 \\
\hline \multicolumn{3}{|c|}{ Estrogen receptor (cut-off 10\%) } \\
\hline Negative & 18 & 36 \\
\hline Positive & 32 & 64 \\
\hline \multicolumn{3}{|c|}{ Progesterone receptor (cut-off 10\%) } \\
\hline Negative & 28 & 56 \\
\hline Positive & 22 & 44 \\
\hline \multicolumn{3}{|l|}{ Her2/neu } \\
\hline Negative (score $0-1$ ) & 36 & 72 \\
\hline Positive (score 2-3) & 14 & 28 \\
\hline
\end{tabular}

of each MMP from the plasma collected before surgery in carcinomas were compared with those of the fibroadenomas. A significant difference was found in MMP 2 concentraion, with values of $257 \pm 17 \mathrm{ng} / \mathrm{ml}$ for carcinomas versus $174 \pm 12 \mathrm{ng} /$ $\mathrm{ml}$ for fibroadenomas; this increase of plasma MMP 2 in carcinoma patients compared with fibroadenoma patients was statistically significant $(\mathrm{P}<0.01$; Fig. 1$)$. The difference between carcinoma and fibroadenoma tissues was not significant for MMPs 3 and 9. The MMP 3 concentration was $110 \pm 7.6 \mathrm{ng} / \mathrm{ml}$ in the carcinomas and $101 \pm 5.5 \mathrm{ng} / \mathrm{ml}$ in the fibroadenomas; the MMP 9 concentration was $65 \pm 5.2 \mathrm{ng} / \mathrm{ml}$ in the carcinomas and $54 \pm 9.2 \mathrm{ng} / \mathrm{ml}$ in the fibroadenomas (Fig. 1).

Comparison of plasmatic MMPs 2, 3 and 9 in breast cancer before and after surgery. The group of carcinoma patients was then analyzed in order to compare the mean values for each MMP obtained before and after surgery. The plasma concentration of each MMP slightly decreased $96 \mathrm{~h}$ after surgery; however the difference between the pre- and post-surgery values was not statistically significant for the three MMPs (Fig. 2). 


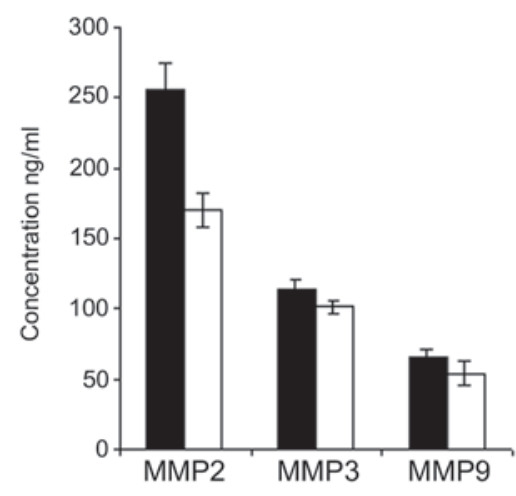

Figure 1. Plasma concentrations (ng/ml) of MMPs 2, 3 and 9 from carcinoma (black columns) and fibroadenoma (white columns) patients. MMP, matrix metalloproteinase.

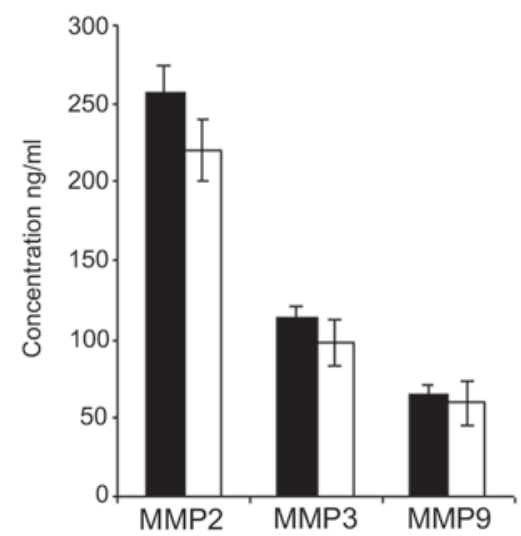

Figure 2. Plasma concentrations (ng/ml) of MMPs 2, 3 and 9 from carcinoma patients in sera collected $24 \mathrm{~h}$ before (black columns) and $96 \mathrm{~h}$ after (white columns) surgery. MMP, matrix metalloproteinase.

Correlation between plasmatic MMPs 2, 3 and 9 and clinicobiological parameters of breast cancer. We next investigated any possible correlation among pre-surgical MMP 2, 3 and 9 plasma concentrations and the clinical and biological parameters of carcinoma patients: $\mathrm{T}$ and $\mathrm{N}$ values, grade, Ki67 level and status of estrogen and progesterone receptors and Her2/neu. The statistical analysis revealed a significant direct correlation between MMP 2 and $\mathrm{G}$ value $(\mathrm{P}<0.01)$ and between MMP 9 and $\mathrm{G}$ value $(\mathrm{P}<0.05$; Table II). No further significant correlation was identified between the other carcinoma parameters analyzed and MMP 2, 3 and 9 concentration. In conclusion, increased concentrations of MMPs 2 and 9 were correlated significantly with the histological grade of the tumor, meaning that a less differentiated breast cancer should be characterized by higher levels of plasma MMPs 2 and 9 .

\section{Discussion}

The role played by MMPs in several steps of cancer local invasion and metastasis is already well known: the increase in levels of these enzymes within the tumor site is due either to tumor cells or to peri-tumoral activated fibroblasts, as well as to inflammatory cells (8-10). In particular, MMP 2 has been studied for its involvement in breast cancer progression, and the positive immunostaining of the enzyme has been
Table II. Correlations between pre-surgical MMPs 2, 3 and 9 and clinical parameters.

\begin{tabular}{|c|c|c|c|}
\hline Clinical parameters & $\begin{array}{l}\text { MMP } 3 \\
\text { basal }\end{array}$ & $\begin{array}{c}\text { MMP } 2 \\
\text { basal }\end{array}$ & $\begin{array}{c}\text { MMP } 9 \\
\text { basal }\end{array}$ \\
\hline \multicolumn{4}{|l|}{ er } \\
\hline $\mathrm{PC}$ & 0.301 & -0.052 & 0.390 \\
\hline Sig. (2-code) & 0.061 & 0.734 & 0.004 \\
\hline $\mathrm{N}$ & 40 & 45 & 37 \\
\hline \multicolumn{4}{|l|}{ pgr } \\
\hline PC & -0.082 & -0.062 & 0.017 \\
\hline Sig. (2-code) & 0.615 & 0.687 & 0.922 \\
\hline $\mathrm{N}$ & 40 & 45 & 37 \\
\hline \multicolumn{4}{|l|}{ erbB } \\
\hline $\mathrm{PC}$ & 022 & 0.028 & -0.090 \\
\hline Sig. (2-code) & 891 & 0.857 & 0.596 \\
\hline $\mathrm{N}$ & 40 & 44 & 37 \\
\hline \multicolumn{4}{|l|}{ ki67 } \\
\hline $\mathrm{PC}$ & 0.030 & -0.308 & -0.082 \\
\hline Sig. (2-code) & 0.854 & 0.390 & 0.630 \\
\hline $\mathrm{N}$ & 40 & 45 & 37 \\
\hline \multicolumn{4}{|l|}{$\mathrm{T}$} \\
\hline $\mathrm{PC}$ & -0.008 & -0.049 & -0.039 \\
\hline Sig. (2-code) & 0.957 & 0.741 & 0.813 \\
\hline $\mathrm{N}$ & 43 & 48 & 39 \\
\hline \multicolumn{4}{|l|}{$\mathrm{N}$} \\
\hline $\mathrm{PC}$ & 0.098 & -0.105 & -0.010 \\
\hline Sig. (2-code) & 0.531 & 0.478 & 0.950 \\
\hline $\mathrm{N}$ & 43 & 48 & 39 \\
\hline \multicolumn{4}{|l|}{ G } \\
\hline $\mathrm{PC}$ & 0.031 & $0.369^{\mathrm{a}}$ & $0.324^{b}$ \\
\hline Sig. (2-code) & 0.842 & 0.010 & 0.044 \\
\hline $\mathrm{N}$ & 43 & 48 & 39 \\
\hline \multicolumn{4}{|l|}{ MMP 3 basal } \\
\hline $\mathrm{PC}$ & 1 & 0.050 & $0.426^{\mathrm{a}}$ \\
\hline Sig. (2-code) & & 0.756 & 0.009 \\
\hline $\mathrm{N}$ & 45 & 41 & 37 \\
\hline \multicolumn{4}{|l|}{ MMP 2 basal } \\
\hline $\mathrm{PC}$ & 0.050 & 1 & 0.023 \\
\hline Sig. (2-code) & 0.756 & & 0.889 \\
\hline $\mathrm{N}$ & 41 & 48 & 39 \\
\hline \multicolumn{4}{|l|}{ MMP 9 basal } \\
\hline $\mathrm{PC}$ & $0.426^{\mathrm{a}}$ & 0.023 & 1 \\
\hline Sig. (2-code) & 0.009 & 0.889 & \\
\hline $\mathrm{N}$ & 37 & 39 & 41 \\
\hline
\end{tabular}

a Significant at 0.01 (2-code). 'bignificant at 0.05 (2-code). MMP, matrix metalloproteinase; er, estrogen receptor; pgr, progesterone receptor; $\mathrm{PC}$, Pearson's correlation.

proposed to be a marker of aggressiveness in breast carcinoma (11); however, it has been demonstrated that blocking MMP 2 secretion and activation may reduce the risk of breast 
cancer metastasis (12). The concentration of specific MMPs has also been described to be enhanced in the serum of tumoral patients, including patients with breast neoplasia (13), and the combined determination of MMP 2, MMP 9 and TIMP1 has been proposed as a significant marker in blood plasma for bladder cancer diagnosis (14). Our data show that, among the three MMPs analyzed, the plasma MMP 2 level was significantly higher in breast carcinoma patients than in fibroadenoma patients. This result agrees with those of a previous study, which reported that blood levels of MMP 2 were higher in breast cancer patients than in healthy blood donors (15). Furthermore, an elevated activity of pro-MMP 2 and pro-MMP 9 has been described in the serum of mammary neoplasia patients and has been correlated with tumor size and lymph node status, indicating the usefulness of these enzymes as staging markers for breast cancer $(16,17)$.

Our results demonstrate that the plasma concentration of all three MMPs decreaseed $96 \mathrm{~h}$ after surgery, but the variations of these values were not statistically significant. These data may be explained by the fact that $96 \mathrm{~h}$ is too soon after the surgery to observe the total recovery of normal MMPs plasma concentration. In fact, the local and systemic inflammation reactions that follow surgery determine an activation of normal cells with an increase of MMPs, therefore a significant decrease of MMPs serum levels becomes evident only 1 month after surgery $(18,19)$.

Further data were obtained with regard to the correlation of MMP 2 and 9 plasma concentrations with the $\mathrm{G}$ value of the tumor. Poorly differentiated tumors correspond to an advanced stage of neoplasia and are classified with a high value of grading (G3). This stage of tumor is usually characterized by higher invasive potential compared with well-differentiated tumors (low grading values of G1 and G2), which usually correspond to tumors with better prognosis.

An important feature of the tumoral invasive phenotype is the capability to produce lytic enzymes, such as MMPs; therefore, an increase in these enzymes may correlate with a more advanced and invasive tumor. Our results supported this theory, with higher MMP 2 and 9 plasma concentrations correlating with a less differentiated cancer phenotype, as indicated by a high grading. A previous study described that the expression levels of MMPs 8, 10, 12 and 27 in breast cancer tissue were correlated with tumor grade, since they were higher in G3 compared with G2 cancers (20).

A study concerning MMP 2 and 9 immunohistochemical expression performed on patients with lymph node-negative breast cancer demonstrated that the co-expression of the two MMPs is an unfavourable prognostic factor for relapse-free survival (21). MMP 2-positive immunoreactivity in lymph node-positive breast cancer has been reported to be correlated with unfavourable prognosis and increased risk of recurrence in both pre- and postmenopausal patients $(22,23)$.

A recent study described a direct correlation of immunohistochemical expression between MMP 2 and cyclooxygenase-2 (COX-2) in invasive ductal breast carcinoma tissues (24); however, the expression of COX-2 may be associated with increased angiogenesis and lymph node metastasis, and it is also correlated with high histological grade and large tumor size in breast cancer (25). Taken together, this information indicates that a direct link exists between MMP 2 and
COX-2 and that they may both be markers of cell invasion and poor prognosis in breast cancer (26). Our data regarding the correlation between plasma MMP 2 and 9 values and tumor histological grade also suggest the consideration of these parameters as molecular markers of tumor invasion, as has been already indicated for COX-2 (27).

These data confirm the role of certain MMPs in the development and progression of breast cancer and are in agreement with recent clinical research proposing the use of new synthetic metalloproteinase blockers in anticancer therapy, including batimastat, marimastat and tetracycline derivates (12). Therefore, these findings suggest the value of the evaluation of plasma MMP 2 and 9 as additional markers for the prognosis of breast cancer.

\section{References}

1. Egeblad M and Werb Z: New functions for the matrix metalloproteinases in cancer progression. Nat Rev Cancer 2: 161-174, 2002.

2. Hanemaaijer R, Verheijen JH, Maguire TM, Visser H, Toet K, McDermott E, et al: Increased gelatinase-A and gelatinase-B activities in malignant vs. benign breast tumors. Int $\mathrm{J}$ Cancer 2: 204-207, 2000

3. Liotta LA: Tumor invasion and metastases - role of the extracellular matrix: Rhoads Memorial Award lecture. Cancer Res 46: $1-7,1986$.

4. Lynch CC and Matrisan LM: Matrix metalloproteinases in tumor-host cell communication. Differentiation 70: 561-573, 2002.

5. Somiari SB, Shriver CD, Heckman C, Olsen C, Hu H, Jordan R, Arciero C, Russell S, Garguilo G, Hooke J and Somiari RI: Plasma concentration and activity of matrix metalloproteinase 2 and 9 in patients with breast disease, breast cancer and at risk of developing breast cancer. Cancer Lett 233: 98-107, 2006.

6. Leppä S, Saarto T, Vehmanen L, Blomqvist C and Elomaa I: A high serum matrix metalloproteinase-2 level is associated with an adverse prognosis in node-positive breast carcinoma. Clin Cancer Res 10: 1057-1063, 2004.

7. Mendes O, Kim HT and Stoica G: Expression of MMP2, MMP9 and MMP3 in breast cancer brain metastasis in a rat model. Clin Exp Metastasis 22: 237-246, 2005.

8. Baker EA, Stephenson TJ, Reed MW and Brown NJ: Expression of proteinases and inhibitors in human breast cancer progression and survival. Mol Pathol 55: 300-304, 2002.

9. Bodey B, Bodey B Jr, Siegel SE and Kaiser HE: Matrix metalloproteinases in neoplasm-induced extracellular matrix remodelling in breast carcinoma. Anticancer Res 21: 2021-2028, 2001.

10. González LO, Pidal I, Junquera S, Corte MD, Vásquez J, Rodríguez JC, Lamelas ML, Merino AM, García-Muñíz JL and Vizoso FJ: Overexpression of matrix metalloproteinases and their inhibitors in mononuclear inflammatory cells in breast cancer correlates with metastasis-relapse. Br J Cancer 97: 957-963, 2007.

11. Talvensaari-Mattila A,PääkköP,Höyhtyä M,Blanco-Sequeiros G and Turpeenniemi-Hujanen T: Matrix metalloproteinase-2 immunoreactive protein: a marker of aggressiveness in breast carcinoma. Cancer 83: 1153-1162, 1998.

12. Jezierska A and Motyl T: Matrix metalloproteinase-2 involvement in breast cancer progression: a mini-review. Med Sci Monit 15: RA32-RA40, 2009.

13. Di Carlo A, Terracciano D, Mariano A and Macchia V: Matrix metalloproteinase-2 and matrix metalloproteinase-9 type IV collagenases in serum of patients with pleural effusions. Int J Oncol 26: 1363-1368, 2005.

14. Staack A, Badendieck S, Schnorr D, Loening SA and Jung K: Combined determination of plasma MMP2, MMP9, and TIMP1 improves the non-invasive detection of transitional cell carcinoma of the bladder. BMC Urol 6: 19, 2006.

15. Incorvaia L, Badalamenti G, Rini G, Arcara C, Fricano S, Sferrazza C, Di Trapani D, Gebbia N and Leto G: MMP-2, MMP-9 and activin A blood levels in patients with breast cancer or prostate cancer metastasis to the bone. Anticancer Res 27: $1519-1525,2007$ 
16. Jinga DC, Blidaru A, Condrea I, Ardeleanu C, Dragomir C, Szegli G, Stefanescu M and Matache C: MMP-9 and MMP-2 gelatinases and TIMP-1 and TIMP-2 inhibitors in breast cancer: correlations with prognostic factors. J Cell Mol Med 10: 499-510, 2006.

17. Stankovic C, Konjevic G, Gopcevic K, Jovic V, Inic M and Jurisic V: Activity of MMP-2 and MMP-9 in sera of breast cancer patients. Pathol Res Pract 206: 241-247, 2010.

18. Quaranta M, Daniele A, Coviello M, Venneri MT, Abbate I, Caringella ME, Di Tardo S, Divella R, Trerotoli P, Di Gennaro M, Schittulli F, Fransvea E and Giannelli G: MMP-2, MMP-9, VEGF and CA 15.3 in breast cancer. Anticancer Res 27: 3593-3600, 2007.

19. Ranuncolo SM, Armanasco E, Cresta C, Bal De Kier Joffe E and Puricelli L: Plasma MMP-9 (92 kDa-MMP) activity is useful in the follow-up and in the assessement of prognosis in breast cancer patients. Int J Cancer 106: 745-751, 2003.

20. Köhrmann A, Kammerer U, Kapp M, Dietl J and Anacker J: Expression of matrix metalloproteinases (MMPs) in primary human breast cancer and breast cancer cell lines: New findings and review of the literature. BMC Cancer 9: 188, 2009.

21. Li HC, Cao DC, Liu Y, Hou YF, Wu J, Lu JS, Di GH, Liu G, Li FM, Ou ZL, Jie C, Shen ZZ and Shao ZM: Prognostic value of matrix metalloproteinases (MMP-2 and MMP-9) in patients with lymph node-negative breast carcinoma. Breast Cancer Res Treat 88: 75-85, 2004.

22. Talvensaari-Mattila A, Pääkkö $P$ and Turpeenniemi-Hujanen T: MMP-2 positivity and age less than 40 years increases the risk for recurrence in premenopausal patients with node-positive breast carcinoma. Breast Cancer Res Treat 58: 287-293, 1999.
23. Talvensaari-Mattila A, Pääkko P, Blanco-Sequeiros G and Turpeenniemi-Hujanen T: Matrix metalloproteinase-2 (MMP-2) is associated with the risk for a relapse in postmenopausal patients with node-positive breast carcinoma treated with antiestrogen adjuvant therapy. Breast Cancer Res Treat 65: 55-61, 2001

24. Atik E, Akansu B, Bakaris S and Aban N: Expression of cyclooxygenase- 2 and its relation to histological grade, inducible nitric oxide synthase, matrix metalloproteinase-2, CD-34, Caspase-3, and CD8 in invasive ductal carcinoma of the breast. Saudi Med J 31: 130-134, 2010.

25. Nassar A, Radhakrishnan A, Cabrero IA, Cotsonis G and Cohen C: COX-2 expression in invasive breast cancer: correlation with prognostic parameters and outcome. Appl Immunohistochem Mol Morphol 15: 255-259, 2007.

26. Sivula A, Talvensaari-Mattila A, Lundin J, Joensuu H, Haglund C, Ristimaki A and Turpeenniemi-Hujanen T: Association of cyclooxygenase- 2 and matrix metalloproteinase-2 expression in human breast cancer. Breast Cancer Res Treat 89: 215-220, 2005.

27. de la Torre J, Sabadell MD, Rojo F, Lirola JL, Salaricru S, Reventos J, Ramón y Cajal S and Xercavins J: Cyclo-oxygenase type 2 is dysregulated in breast ductal carcinoma in situ and correlates with poor outcome. Eur J Obstet Gynecol Reprod Biol 151: 72-76, 2010 